\title{
PARTICIPAÇ
}

OCIAL NA SAÚDE INDÍGE A APOSTA CONTR ASSIMETRIA NO BRA 


\section{PARTICIPACÃO SOCIAL NA SAÚDE INDÍGENA: A APOSTA CONTRA A ASSIMETRIA NO BRASIL?}

\section{CARLA COSTA TEIXEIRA}


PARTICIPAÇÃO SOCIAL NA SAÚDE INDÍGENA: A APOSTA CONTRA A ASSIMETRIA NO BRASIL?

\title{
Resumo
}

Este artigo enfoca as práticas discursivas dos indígenas na luta pela redução das assimetrias nas políticas de saúde brasileiras. Nessas o discurso da "interculturalidade" se faz quase ausente, diferente do observado nas políticas de educação e em várias políticas indigenistas em outros contextos latino-americanos. O escrutínio de situações e documentos mostrou a ênfase na "participação social" e "atenção diferenciada". A questão é qual o significado de não tomar o eixo da cultura, implícito na categoria "interculturalidade", como mediador da defesa dos direitos indígenas na saúde? Para tal apresenta o subsistema de saúde indígena, se detém na $5^{\mathrm{a}}$ CNSI para refletir sobre a categoria "participação social" e estabelecer um diálogo entre "atenção diferenciada" e "interculturalidade", propondo que a luta dos indígenas na saúde tem se dado nos termos de garantir um diferencial de poder (político-estratégico e moral) a ser revertido a seu favor e não principalmente como conquista de direitos substantivos.

Palavras-chave: saúde indígena; interculturalidade; participação social; cidadania; antropologia política da saúde

\section{SOCIAL PARTICIPATION IN INDIGENOUS HEALTH: BETTING AGAINST ASSIMETRY IN BRAZIL?}

\begin{abstract}
This manuscript focuses on indigenous discursive practices in the struggle to reduce asymmetries in Brazilian health policies. In these, the "interculturality" discourse is almost absent, different from the one observed in education policies and in several indigenist policies in other Latin American contexts. The scrutiny of situations and documents showed the emphasis on "social participation" and "differentiated attention". The question is what is the meaning of not taking the axis of culture, implicit in the "interculturality" category, as mediator of the defense of indigenous rights in health? To that end, the indigenous health subsystem is presented, and the 5th CNSI is held in order to reflect on the "social participation" category and to establish a dialogue between
\end{abstract}


"differentiated attention" and "interculturality", which proposes that the indigenous struggle in health has been given in terms of ensuring a power differential (political-strategic and moral) to be reversed in their favor and not primarily as an achievement of substantive rights.

Keywords: indigenous health, interculturality, social participation, citizenship, political anthropology of health.

\section{PARTICIPACIÓN SOCIAL EN LA SALUD INDÍGENA: ¿LA APUESTA CONTRA LA ASIMETRÍA EN BRASIL?}

\section{Resumen}

Este artículo se enfoca en las prácticas discursivas de los indígenas en la lucha por la reducción de las asimetrías en las políticas de salud brasileras. En ellas, el discurso de la "interculturalidad" está casi ausente, diferente a lo observado en las políticas de educación y en varias políticas indigenistas en otros contextos latinoamericanos. El escrutinio de situaciones y documentos mostró que el énfasis está puesto en la "participación social" y en la "atención diferenciada". La cuestión es ¿cuál es el significado de que no se tome el eje de la cultura, implícito en la categoría de "interculturalidad", como mediador en la defensa de los derechos de la salud indígena? Para este fin, se presenta el subsistema de salud indíge-

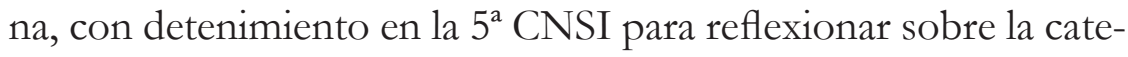
goría "participación social" y establecer un diálogo entre "atención diferenciada" e "interculturalidad", proponiendo que la lucha de los indígenas en salud se ha dado en términos de garantizar un diferencial de poder (politico-estratégico y moral) a ser revertido a su favor y no principalmente como conquista de derechos sustantivos.

Palabras clave: salud indígena; interculturalidad; participación social; ciudadanía; antropología política de la salud

Carla Costa Teixeira

carla.c.teix@gmail.com 
A indagação que intitula este artigo me foi inspirada por um convite a participar do painel "Estado y Asimetría" durante o III Encuentro de Antropología México-Brasil em 2015 na cidade de Guadalajara. Na descrição resumida das reflexões que levaram à proposição desse painel a ênfase na discussão da "interculturalidad" era evidente. Foi, então, que a quase ausência do debate em torno dessa categoria na saúde indígena no Brasil me chamou atenção. A partir da leitura de vários documentos legais, dos relatórios das cinco conferências nacionais de saúde indígena, da experiência na Comissão Intersetorial de Saúde Indígena/CISI ${ }^{1}$ e da participação como relatora na $5^{\mathrm{a}}$ Conferência Nacional de Saúde Indígena/5a CNSI percebi o quão pouco a "interculturalidade" organizava as ações políticas dos indígenas na saúde. Construí, então, um percurso para buscar compreender como, diferente da atuação dos indígenas nas políticas de educação, na política de saúde a busca pela redução das assimetrias entre indígenas e não indígenas se dava por meio de outras práticas discursivas.

Com tal perspectiva, a reflexão que pretendo desenvolver tem como referência a atuação de lideranças e representantes indígenas nas políticas de governo para a saúde dos povos indígenas no Brasil. A hipótese, como o título sugere, é que os mecanismos formais de participação social têm sido nas últimas décadas a principal via política para a construção e efetivação dos direitos indíge- nas na saúde e superação da assimetria que se perpetua historicamente e se expressa em indicadores de saúde frequentemente duas vezes piores do que os da população não indígena ${ }^{2}$.

Um olhar mais acurado para situações e documentos produzidos neste percurso permite também perceber que, diferente do que ocorre em outros contextos latino-americanos, "atenção diferenciada" é a categoria política que orienta tais ações; em detrimento da categoria de "interculturalidade" tão presente nos contextos mexicano, chileno e boliviano só para citar alguns ${ }^{3}$. Se considerarmos que essa é uma categoria que pretende constituir e administrar as diferenças como "culturais" (Boccara \& Bolados 2010), o que sua não centralidade pode nos dizer sobre as disputas em torno da cidadania indígena nas políticas de saúde?

Tendo em vista este conjunto de preocupações, o artigo primeiro apresenta em linhas gerais a configuração organizacional do subsistema de saúde indígena, destacando o "controle social" - como é chamada a participação na saúde -, para então focalizar a $5^{\text {a }}$ Conferência Nacional de Saúde Indígena ocorrida em 2013. Com os pés firmes neste terreno empírico buscar-se-á, por um lado, desdobrar a discussão sobre os efeitos da participação social indígena e, por outro, compreender a configuração da cidadania indígena no Brasil e o não privilégio da interculturalidade em sua tessitura na arena das políticas de saúde 4 . 


\section{- SUBSISTEMA DE SAÚDE INDÍGENA}

A reforma sanitária que transformou a saúde em direito de todos os cidadãos e dever do Estado em 1988, com a nova constituição, tinha como desafio melhorar as condições de saúde, mas também democratizar a própria política de saúde. Nesse sentido, para a saúde indígena foi organizado um subsistema voltado à atenção básica de saúde dentro do Sistema Único de Saúde (SUS) no início dos anos 90. Esse subsistema, contudo, só foi possível no processo de redemocratização que marcou o final do século XX graças à articulação entre o movimento indígena e o movimento pela universalização do sistema de saúde que buscou traduzir a bandeira abrangente, que afirmava a saúde como dever do Estado, para uma agenda voltada para as singularidades dos povos indígenas (Teixeira et al. 2013). Assim, logrou-se assegurar condições políticas para a construção de um sistema de saúde diferenciado vinculado ao Ministério da Saúde (MS), e não mais ao órgão indigenista (Fundação Nacional do Índio - FUNAI), e no qual estivesse assegurada a participação indígena. Incialmente sob a gestão da Fundação Nacional de Saúde (FUNAS), em 2010 passou à responsabilidade da recém-criada Secretaria Especial de Saúde Indígena integrando a própria estrutura ministerial.

Tal processo de passagem de uma política de saúde tutelar e assistencial implementada pelo órgão indigenista (FUNAI) para uma política universalista e orientada pela justiça social do SUS tem sido, no entanto, marcado por um movimento espiralado e não linear devido a um conjunto de elementos que não se esgotam na disputa explicitamente política dos direitos diferenciados indígenas, mas envolvem dispositivos burocráticos, gerenciais, técnicos e mediações contextuais complexas como bem analisou Garnelo (2014).

É nessa configuração que o subsistema de saúde indígena foi criado em 1999 com seus 34 Distritos Sanitários Especiais Indígenas (DSEI) organizados territorialmente para prover ações de atenção básica de saúde aos indígenas localizados em sua área e encaminhá-los e acompanha-los nos serviços de atenção de maior complexidade no SUS. E, no que nos interessa mais diretamente aqui, essa estrutura sanitária orientou uma organização singular do controle social indígena em conselhos locais (nas aldeias), em conselhos de representantes nos DSEI (conselhos distritais) e, desde 2006, com representação em nível nacional no Conselho Nacional de Saúde (CNS) e exercendo a coordenação da Comissão Intersetorial de Saúde Indígena (CISI) na qual detêm a maioria dos assentos ${ }^{5}$. Esses conselhos, seguindo normatização que reestruturou o CNS em $1990^{6}$, devem ter a seguinte composição: $50 \%$ de usuários e $50 \%$ de trabalhadores, gestores e prestadores de serviço de saúde - com exceção dos conselhos locais que podem ser compostos apenas por indígenas e são somente consultivos. Os conselhos distritais, por sua vez, se articulam através de seus presidentes em reuniões periódicas no Fórum de Presidentes de Conselhos Distritais de Saúde Indígena (FCondisi) promovi- 
das pelo gestor federal (primeiro a FUNASA que o criou em 2006 e, depois de 2010, a SESAI).

Essa é a estrutura permanente do controle social indígena ${ }^{7}$. Uma estrutura que foi produzida por e produz muitos documentos normativos (decretos presidenciais; portarias ministeriais; resoluções, recomendações, moções e deliberações dos conselhos), dentre os quais se destaca a Política Nacional de Atenção à Saúde dos Povos Indígenas em $2002^{8}$ que, fazendo referência às duas conferências nacionais de saúde indígena e às duas conferências nacionais de saúde de 1986 e 1993, estabelece como propósito de política de governo garantir o acesso integral dos indígenas à saúde por meio de um duplo movimento: respeitar os princípios e diretrizes universalistas do SUS e, simultaneamente, contemplar a diversidade social, cultural, geográfica, histórica e política. Dessa perspectiva, reitera a adoção de um modelo complementar e diferenciado de organização dos serviços que veio a ser abreviado na expressão "atenção diferenciada" nos debates políticos, assumindo sentidos diversos a depender do contexto e dos interlocutores - ora referindo-se ao modelo de gestão (Cardoso 2015), ora às ações de atenção à saúde (Langdon et al. 2014).

Contudo, o controle social não se esgota nesses espaços. Para se ter uma ideia da extensão e dos múltiplos efeitos dessa "gestão estratégica e participativa", que tem como atribuição institucional a "formulação, acompanhamento e avaliação das políticas públicas de saúde", ${ }^{\prime}$, resta introduzir outra forma de participação, apenas mencionada acima: as conferências nacionais de saúde indígena. Embora as conferências nacionais estejam previstas para ocorreram a cada quatro anos, essa periodicidade não se manteve no caso das conferências específicas para a saúde indígena: a Conferência Nacional de Proteção à Saúde do Índio foi a primeira e se reuniu em 1986, a II Conferência foi em 1993, a III Conferência em 2001, a $4^{\mathrm{a}}$ Conferência em 2006 e a $5^{\mathrm{a}}$ Conferência somente em 2013. Assim, sua relevância não deve ser buscada em sua função oficial de fazer diagnósticos e propor orientações para as políticas de governo de saúde indígena, nem tampouco na capilaridade de governança gerada pelas formas permanentes do controle social esboçadas acima. Antes de avançar nesta reflexão sobre a especificidade das conferências como um dispositivo de poder, contudo, é importante nos determos na experiência de uma conferência: a $5^{a}$ Conferência Nacional de Saúde Indígena (5a CNSI). A escolha dessa conferência, que ocorreu em Brasília nos dias 2 a 6 de dezembro de 2013, deve-se ao fato de ter sido a maior conferência em termos de delegados com direito a voto, participantes e convidados - e, principalmente, porque tive a oportunidade de observa-la e circular em seus diferentes espaços compondo a equipe de relatoria.

\section{$5^{a}$ CONFERÊNCIA NACIONAL DE SAÚDE INDÍGENA}

A $5^{\mathrm{a}}$ CNSI reuniu 1.226 delegados dentre os quais 589 eram delegados in- 
dígenas vindos de todas as regiões do país ${ }^{10}$, além de 35 convidados de articulações indígenas, organizadores, equipe de apoio, imprensa etc. que totalizaram 1.907 participantes (Ministério da Saúde; Conselho Nacional de Saúde 2015:146). Durante cinco dias grupos de trabalho votaram as propostas vindas de 306 conferências da etapa local e das 34 da etapa distrital, organizadas por eixos temáticos, sendo as propostas controversas levadas para a plenária final. Sob o tema central "Subsistema de Saúde Indígena e SUS: direito, acesso, diversidade e atenção diferenciada" foram aprovadas 453 propostas que se encontram listadas no relatório final da conferência. Numa grande celebração de sucesso antecipado, a $5^{\text {a }}$ CNSI foi marcada por poucos debates (os grupos só podiam referendar as propostas vindas das etapas anteriores e suprimir partes, mas não acrescentar nada) e muitas votações, tanto nos grupos quanto na plenária final, por meio de levantamento dos crachás pelos delegados.

Em sua fala de saudação de abertura, o então secretário especial de saúde indígena Antonio Alves, após citar alguns dados exaltando a ampla participação dos indígenas no processo que culminou na $5^{\mathrm{a} C N S I}$, concluiu:

O que traduz o envolvimento de um grande número de pessoas, organizadores e participantes destas conferências, e atesta a aposta que a comunidade indigena brasileira faz na democracia participativa. Tamanha mobilização nos dá a clara noção da responsabilidade que repousa sobre este momento, como também dos desafios colocados para os pró- ximos quatro anos do SasiSUS e do Brasil (Ministério da Saúde; Conselho Nacional de Saúde 2015:21. Grifos meus).

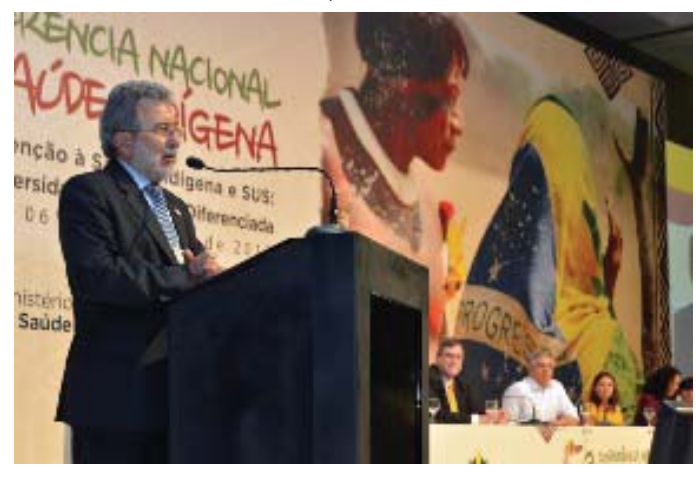

Figura 1 - Secretário Especial de Saúde Indígena, plenária de abertura da $5^{\mathrm{a}} \mathrm{CNSI}^{11}$

Nesta ocasião, além de participar da comissão de relatoria, realizamos ${ }^{12}$ um documentário e fizemos quase 30 entrevistas com diferentes participantes, em sua maioria indígena, e obtivemos distintas avaliações e concepções sobre a conferência e o controle social em geral, algumas otimistas outras nem tanto:

Com a criação da Secretaria Especial da Saúde Indígena, isso pra gente deu um passo maior para o movimento indígena, né? Daí então vem se avançando uma política de saúde para os nossos povos indígenas, no qual nós estamos participando diretamente do controle social. Não só nas ações em fiscalizar as ações e serviços de atenção à saúde indígena, mas nós podemos estar discutindo também um governo, um modelo da saúde indígena que nós queremos. Também nós vemos um avanço, é tanto que o recurso da saúde indígena triplicou, né, em pouco tempo... (vice-presidente de Condisi, William Xakriabá)

Eu lembro que nas conferências anteriores como proposta a gente 
colocava "nós queríamos que os distritos sejam autônomos" né, politicamente, financeiramente, tudo isso. Aí a gente falava também que fosse criado um órgão, uma secretaria específica pra cuidar da saúde indígena (...) A diferença dessa conferência é que esses assuntos já não discutimos mais porque essas coisas a gente já conquistou (coordenador executivo do Fórum de presidentes de Condisi, Jorge Marubo) Desde o princípio SESAI que foi criada, a nossa intenção, do próprio fórum dos presidentes, do conselho distrital, e até do movimento indígena organizado, como a COIAB, a nossa vontade é ficar na linha de frente, para que próprio indígena exerça a sua função, dentro da sua realidade, trabalhar. De maneira mais transparente. Mas não. (...) Moral da história: a visão da sociedade envolvente, quem tá na linha de frente de qualquer instituição pensa: o índio não tá preparado. (coordenador da CISI, Edmundo Omore)

Enquanto a gente estava aqui durante essa semana, houve vários casos de morte nas regiões. Então, a gente tá discutindo, mas as coisas não param e as situações continuam acontecendo nas regiões. Então, não dá pra gente ficar esperando mais muito tempo. As propostas aqui aprovadas precisam de fato ser consideradas pelo Estado brasileiro, pelo governo brasileiro, pelo Ministério da Saúde, e que haja essas condições pra que elas possam de fato ser concretizadas porque se fica no papel como as outras conferências, aí não adianta mais ficar fazendo conferências, apenas pra conferir o que tá ruim? (coorde- nadora executiva da APIB, Sônia Guajajara)

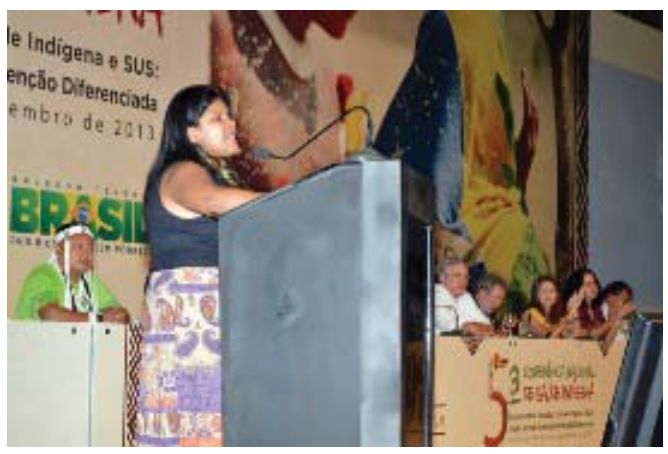

Figura 2 - Coordenadora Executiva da APIB, plenária de abertura da $5^{a} \mathrm{CNSI}^{13}$

Eu achei tão bonito, mas, no meu coração, eu sentia dizendo assim, "Vocês não esperem sair, pois no papel foi feito bunitim, abre a boca e diz que foi aprovado, mas pra chegar lá nas base, pra chegar lá no indígena o recurso e melhorar - pra melhorar a saúde....”. (delegada Esmeralda Jaminawa-Arara)

Há um movimento indígena muito fortalecido em relação ao que de fato é, o que de fato é... almeja, mas a gente não consegue fazer um controle social, ou seja, articulado. Existem dois movimentos: um movimento que dialoga muito de pertinho, que... que não bate de frente; e aí tem um movimento indígena, que é aquele que vai pra rua, que manifesta, que grita - esse sim é um movimento que luta pela saúde. (coordenador da ARPINSUL, Rildo Kaingang)

Em que pese as diferentes perspectivas sobre as conferências e as relações entre o controle social, os representantes estatais e o movimento indígena que serão retomadas adiante, há certo consenso entre os indígenas, por um lado, sobre a baixa efetivação das decisões aí tomadas e, por outro, num aparente 
paradoxo, sobre a relevância política do controle social e a necessidade de aprimora-lo - seja por sua função pedagógica na atuação política, seja pelo projeto de assunção da gestão do subsistema pelos próprios indígenas ou pela sua potência para garantir direitos diferenciadas. O que vem a confirmar a conclusão do então secretário da SESAI sobre a aposta indígena transcrita anteriormente, mas apenas parcialmente como veremos na próxima parte do artigo.

Antes há que destacar que tal aposta na democracia participativa no Brasil tem se dado não apenas na saúde indígena. Observamos a organização de conselhos e conferências em distintas estruturas de governo com avaliações similares e, por vezes, mais críticas ainda quando os conselheiros afirmam ser baixa a influência do controle social nas políticas de governo (IPEA 2013; 2013a) - autoimagem que o controle social na saúde e em especial os indígenas não compartilham. Neste sentido, parece que a escolha e a ênfase nessa via de atuação se sustentaria na importância da multiplicação das arenas de participação e seus efeitos políticos, que efetivamente ocorreram, e não pela confiança de que suas decisões sejam efetivadas. Daí a sensação manifesta pelos indígenas de que a mudança no cotidiano da saúde tem se dado de forma lenta e que suas decisões em geral não sairiam do papel para a realidade nas aldeias. Assim, tratar-se-ia de uma perspectiva de democracia que parece enfatizar mais os procedimentos e menos os resultados. Embora na saúde indígena tenham sido muitos os avanços conquistados na construção de políticas de governo, pouco se tem obtido como melhoria das condições de saúde dos povos indígenas por meio da participação.

Mas se até agora tenho usado "participação social” de forma naturalizada, como o fazem os sujeitos em suas práticas e discursos políticos, é preciso fazer ponderações mais cuidadosas para avançar na reflexão aqui proposta.

\section{PARTICIPAÇÃO SOCIAL}

O termo "participação social" é parte do vocabulário das políticas neoliberais, juntamente com outros como "parceria" e, assim, evoca a relação necessária entre direito e dever: ao direito à saúde corresponde o dever de participar - além, não podemos esquecer, dos deveres relativos à incorporação das orientações da educação sanitária (Teixeira \& Silva 2015). E, sobretudo, constitui uma técnica de gestão, tão ao gosto dos projetos de desenvolvimento, que cria uma espécie de cidadania burocrática ao transformar os sujeitos de direitos em co-gestores do governo, as identidades políticas em funções administrativas (Teixeira 2008; Bronz 2016; Salviani 2010, 2013; Boccara \& Bolados 2010).

Mas a participação é também uma reivindicação dos movimentos sociais com vistas a garantir e fazer avançar direitos sociais universalizáveis e específicos. Em certo sentido, seria um desdobramento da expansão do associativismo no período democrático brasileiro. No caso dos povos indíge- 
nas tal processo é intenso e se dá via associações diversas e articulações indígenas regionais e nacionais, com forte presença em políticas públicas: saúde, educação, gestão ambiental etc. Contudo, como ouvimos de diferentes indígenas na 5aCNSI, há por parte de vários a compreensão de que a participação social é importante, mas que requer uma outra ação que a complemente: a luta por fora das instâncias estatais mobilizada pelas associações e articulações indígenas, expressando assim uma confiança desconfiada (expressa na fala do coordenador da ARPINSUL, acima transcrita) das possibilidades políticas da participação social ${ }^{14}$.

O reconhecimento dos limites da participação social parece se dar também em outra direção, além daquela indicada pela afirmação da importância dos movimentos sociais indígenas. Refiro-me ao fato de que os indígenas reivindicam e têm cada vez mais obtido lugares dentro da gestão, como assessores indígenas nos Dsei, como profissionais da saúde e explicitamente (como na fala do coordenador da CISI, acima transcrita) almejam assumir postos com maior poder de decisão na saúde, ou seja, buscam aprofundar sua capacidade de atuação também por dentro das instâncias estatais. Afinal, como se escuta informalmente: quem pode manda, quem não pode participa. Desta perspectiva, a participação social seria uma tática na obtenção de expertise no manejo da administração da saúde indígena.

Assim, articulando ações dentro e fora dos espaços burocráticos estatais os indígenas algumas vezes logram explicitar a dimensão política das ações estatais sempre apresentadas como obedecendo a normas e princípios de "eficácia, eficiência e efetividade" - como se diz no jargão dos gestores e dos avaliadores de políticas públicas. Mas por vezes são capturados pela arena administrativa com sua temporalidade, terminologia, documentos, definição de metas etc., na qual os conflitos políticos são domesticados e transformados em questões gerenciais. É um processo em curso, tenso, que tem exigido decisões difíceis das lideranças indígenas e pleno de idas e vindas.

O campo da participação social, portanto, parece ser um espaço de disputa no qual está em jogo a luta permanente por definir conexões e afirmar o vínculo intrínseco entre a gestão concebida como técnica e o gestar próprio à criatividade da política (Souza Lima 2003). Dito de outra forma, se o que caracteriza os governos contemporâneos é a transformação das lutas sociais, sejam étnicas, de classe ou de gênero em tecnicidades de governo; a participação social tem a possibilidade de re-politizar os processos estatais, ao trazer para o debate dentro das esferas administrativas a experiência da vida cotidiana e da luta contra a injustiça social que qualifica os movimentos sociais

A tensão entre tecnificação da política e re-politização da técnica é permanente nesses processos em que se sentam à mesa gestores, trabalhadores da saúde e lideranças indígenas. Ora tendendo para um polo, ora para o outro num processo de fazer-se Estado: um estado-sistema e também um estado-configuração de ideias (Abrams 1988). 
Em outras palavras, os indígenas atuam instrumentalmente nos espaços do estado-sistema em busca de resultados nas ações de governo ou usando-o como pedagogia política, mas também no estado-ideia pelos efeitos da encenação espetacular da participação política em si. Efeitos que podem criar as próprias condições da governança da saúde pelos indígenas mesmo que apenas momentaneamente, como desdobramento da dimensão simbólica do exercício do poder e da legitimidade dele decorrente. Assim, na conferência em foco os indígenas deixaram de lado as bordunas, cuja ausência muitos comentaram, para fazer uma demonstração de cidadania participativa com suas camisetas coloridas e crachás de delegados, compondo mesas lado a lado com autoridades de governo ou quebrando protocolos para denunciar as péssimas condições de saúde como o fizeram os delegados do Mato Grosso do Sul. E, por meio dessa tática, aprovaram propostas e moções de seu interesse, viraram notícia nas mídias, principalmente, nas mídias sociais e se apresentaram como cidadãos plenos.

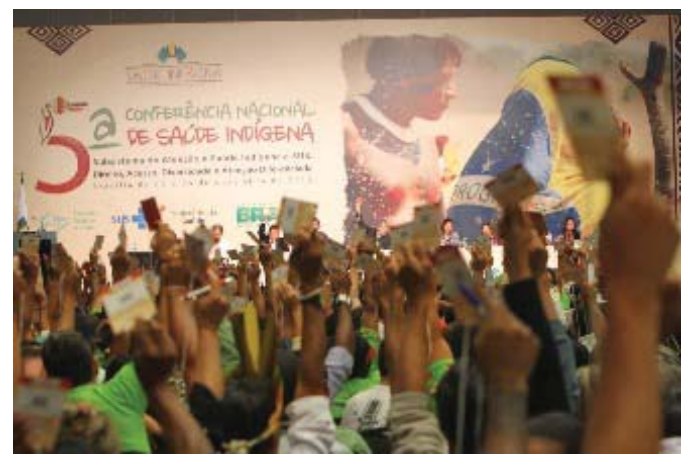

Figura 3 - Votação na Plenária Final da $5^{a}$ $\mathrm{CNSI}^{15}$

Esta é a meu ver a relevância das conferências nacionais na estruturação do controle social, muito diferente das suas instâncias permanentes locais e nacionais: constituem uma cena participativa (Bronz 2016) que possibilita teatralizar a participação social em seu maior esplendor e, assim, encenar também a força da organização dos povos indígenas e suas prioridades de luta.

\section{ALINHAVOS FINAIS: E A INTERCUL- TURALIDADE?}

Contudo nas diferentes cenas participativas, mas também nas práticas de atenção à saúde indígena, são a participação e a atenção diferenciada (Cardoso 2015) as categorias presentes. Se olharmos para o relatório final da $5^{a} \mathrm{CNSI}$, como já o fiz em outra oportunidade para as conferências anteriores no que se refere à autonomia e participação (Teixeira 2010), constatamos que "participação" aparece 110 vezes, "atenção diferenciada" e termos correlatos (assistência diferenciada, saúde diferenciada, atendimento diferenciado etc.) aparece 54 vezes - além de fazer parte do tema central que dá título à conferência - e intercultural ou interculturalidade aparece apenas 5 vezes. Ou seja, definitivamente não é o dispositivo discursivo priorizado pelos indígenas na luta pela saúde. Sem qualquer pretensão de chegar a uma conclusão precipitada, avalio que é necessário ver as especificidades do campo da saúde pública no Brasil para entender tal ausência. Antes, porém, traçarei em linhas gerais a trajetória da interculturalidade num horizonte maior.

De início cabe destacar que, como adjetivo ou substantivo, a interculturali- 
dade nasce no mesmo ambiente que a participação social: os organismos internacionais de financiamento dos países denominados em desenvolvimento como o Banco Mundial e o Banco Interamericano de Desenvolvimento, além dos organismos específicos da saúde, a saber, a Organização Pan-americana de Saúde e a Organização Mundial de Saúde. Nas palavras de Aizenberg ao historicizar o processo para analisar a situação na Bolívia (2011):

Desde mediados de la década de 1990, distintas agencias internacionales comenzaron a diseñar la "Estrategia Mundial de Desarrollo com Identidad" con la intención de aplicarla en los países en desarrollo. Tal Estrategia obligó a las agencias a destinar fondos específcos para el desarrollo de las poblaciones indígenas y a fnanciar acciones desde uma perspectiva de adecuación cultural. Esta preocupación por las necesidades de dichas comunidades no fue casual. Por esa época, las agencias internacionales se encontraron con el gran desafío de combatir las inequidades sociales que habían quedado como saldo de las reformas del Sector Salud de los ochenta y principios de los noventa. El diagnóstico del impacto de dichas reformas mostró una alta brecha entre los indicadores de las comunidades originarias y los de la población no indígena, em especial, en los referidos a la salud reproductiva; y la conclusión a la que arribaron los organismos fue categórica: los bajos índices de salud de las mujeres indígenas se debían a las barreras culturales que obstaculizan su acceso a los servicios de salud modernos. (pp.2)
No ano anterior Boccara \& Bolados (2010), refletindo sobre o processo no Chile também haviam destacado:

Ahora bien, este nuevo interés por las etnias originarias y sus culturas se acompaña del asentamiento de nuevos métodos de intervención. Los múltiples y nuevos agentes a cargo de la política multicultural se hacen presentes en terreno e incitan a los indígenas a actuar, a participar, a expresar sus opiniones, a pensar en «etnodesarrollarse». Se busca establecer una suerte de partnership entre las comunidades indígenas y las distintas agencias estatales y para-estatales. En lugar de intervenir desde el exterior, de manera discrecional o asistencialista, múltiples agencias procuran involucrar a los indígenas en los proyectos de etnodesarrollo, buscan responsabilizarlos y pretenden, siguiendo el lema del Banco Mundial, «ayudarlos a que se ayuden a sí mismos». En fin, como lo formula explícitamente el flamante Programa de etnodesarrollo Orígenes, se trataría de «construir juntos un nuevo camino» (pp. 653).

Se a gestão da diversidade se redefiniu politicamente na redemocratização brasileira movendo-se, ainda que de forma ambígua, da assimilação e da tutela dos índios para a afirmação do seu direito a viver segundo suas tradições e da sua capacidade civil, o paradigma da multiculturalidade não teve aqui o mesmo desenvolvimento na construção da nova nação brasileira que teve nos contextos nacionais referenciados acima. O Brasil não se transformou em uma nação multicultural constitucionalmente falando e sua tradução em 
interculturalidade na saúde também não se aprofundou - em que pesem os trabalhos antropológicos que investem na categoria "intermedicalidade" em sua maior capacidade de expressar as relações de poder (Fóller 2004; Scopel et al. 2015). Aqui é importante reafirmar, para que leituras equivocadas do meu argumento sejam evitadas, que este artigo não aborda a interculturalidade como uma realidade externa aos sujeitos políticos que, então, com ela têm que lidar de uma forma ou de outra. Trata-se, para as preocupações inicialmente explicitadas, de um repertório político e de saberes que produzem um tipo de postulação de realidade que engendra novas formas de poder, mas tais formas são vividas pelos sujeitos políticos e, com frequência, pesquisadas e analisadas pelos cientistas sociais e da saúde como um "plus" na vida democrática, ou seja, como um avanço ou conquista dos indígenas, maior ou menor a depender de quem fala. Muitos diagnósticos têm sido feitos sobre o sucesso ou insucesso dessas iniciativas na saúde indígena (Menéndez 2016; Aizenberg 2011), outros discutem os sentidos de interculturalidade e os remontam à teoria de aculturação (Ferreira 2015) ou analisam criticamente sua despolitização quando passa a integrar o léxico da política de governo (Boccara 2015).

A etnografia do embate político e das negociações entre lideranças indígenas e agentes estatais na definição de uma política de governo na capital federal - na $5^{\text {a }}$ CNSI e nas reuniões trimestrais da CISI - permitiu ver o caráter relacional e contextual dos argumentos acionados na proposição e avaliação da política de saúde indígena. Mas, principalmente, destacou a centralidade da defesa do direito ao exercício do poder pelos indígenas, e para os indígenas, na construção de sua cidadania diferenciada. Com tais afirmações quero destacar que a preservação de uma prática cultural em si não parecia ser a questão central em nenhum momento, mesmo quando se tratava das práticas tradicionais de saúde indígena. Como bem ponderou Cardoso (2015) não é no plano dos serviços terapêuticos que se articulam os conflitos na saúde indígena:

Do ponto de vista dos gestores, promover a atenção diferenciada no âmbito do Sistema Único de Saúde poderia gerar não só conflitos na assistência a ser prestada, mas também sugerir o usufruto de determinados "privilégios" por parte dos indígenas em um modelo de atenção à saúde que pressupõe a "equidade", assim como a assimilação das populações assistidas ao modelo gestor das políticas de saúde pública. Do ponto de vista indígena, entretanto, trata-se cada vez mais de salvaguardar politicamente essa noção, dado que seria por meio da "atenção diferenciada" que a especificidade e a própria manutenção do subsistema de saúde indígena poderia ser mantido diante da tendência crescente do seu pleno abarcamento ao SUS (pág. 97)

Nem tampouco os indígenas atuavam tomando como pressuposto que estavam em um espaço político cuja característica principal era ser "intercultural" e que deveriam assim orientar-se. O que saltou aos olhos foi um processo de articulação diferenciada de vários 
recursos para garantir o reconhecimento do direito dos indígenas conduzirem a estruturação da política e do serviço de saúde indígena que, ao fim, provê o enquadramento institucional da atenção à saúde nas aldeias. Daí a centralidade não só da "participação", mas também da "autonomia" e da "atenção diferenciada" nas disputas, mais ou menos veladas, entre representantes indígenas e gestores, bem como nos relatórios das conferências em diferentes dimensões da política de saúde indígena (Teixeira 2010). Deste modo os indígenas, na posição de lideranças ou de usuários do serviço de saúde, lograram escapar das armadilhas da cidadania culturalista, ou seja, de terem que permanecer atemporais para permanecerem indígenas e, principalmente, de sucumbirem todas as assimetrias (econômicas, sociais, políticas etc.) sob o manto da diferença cultural. Afinal, esse tem sido o entendimento de diversidade cultural nas políticas de governo no Brasil e também em vários outros contextos nacionais - daí, talvez, que a noção de interculturalidade esteja recentemente começando a compor o léxico governamental na saúde indígena ${ }^{16}$. Enquanto a prioridade das lideranças indígenas continua a ser a atenção diferenciada que se articula em um subsistema de saúde dentro do SUS para os indígenas, mas que com ele não se confunde, e no qual buscam nem sempre de forma explícita assumir gradualmente a sua gestão plena, passando pelo exercício da participação e do controle social.

É claro que há conexões contextuais entre ambas as categorias, mas não se recobrem ou se confundem. O cam- po de significados da interculturalidade parece ser no Brasil mais avesso à politização e mais próximo a noções de "diálogo", "encontros", "capacitação" e "competências comunicativas". Já a atenção diferenciada insere-se no espaço semântico das demandas por "respeito", "direito", "atendimento diferenciado". E, o mais importante, é a categoria política da luta por direitos acionada no Brasil pelos indígenas na saúde.

Desta perspectiva, considero que o exercício da cidadania pelos indígenas tem construído a garantia da diversidade e da diferença como um diferencial de poder (político-estratégico e moral) a ser revertido a seu favor e não apenas, embora também o seja, como a conquista de direitos substantivos específicos e garantidores de sua particularidade. Tal deslocamento vem a permitir que as fronteiras entre indígenas e não-indígenas permaneçam dinâmicas e demarcadas conforme as prioridades políticas, históricas, culturais e sociais vividas pelos povos indígenas em cada situação e a cada momento. Assim, a luta indígena por uma cidadania diferenciada e por autodeterminação e autonomia se afinam mais uma vez no campo da saúde indígena contemporâneo na busca por reduzir as assimetrias na saúde. Buscando ir na contramão do "índio permitido", mencionado por Halle (2004) em referência a uma colocação oral de Silvia Rivera, os indígenas atuariam em espaços de negociação por meio da participação com foco nos eixos de conflito, investindo assim em ampliar suas margens de atuação e colocar em cheque o permitido. Afinal, 
nos termos discutidos nos working $p a$ pers do Banco Mundial com objetivo de definir, mensurar e promover o capital social:

Ethnicity is double edged. On the one hand, ethnic groups promote the forces of modernization (...) On the other hand, ethnic groups organize politically; occasionally they engage in acts of violence (...) Ethnic groups can thus both generate benefits and inflict costs on societies. (Bates 1999:1)

Avançar em compreender como os representantes indígenas têm manejado a potência desses dois efeitos na arena política, jogando simultaneamente com o conflito e a denúncia e com a cena e o elogio da participação, me inspirou a atualizar aqui as reflexões desenvolvidas sobre a aposta indígena na participação social no campo da saúde há dois anos em Guadalajara. Sem dúvida, esse percurso ganhou estímulo especial no difícil contexto político dos últimos anos no qual forças anti-indígenas vocalizam cada vez mais suas posições e as fazem valer e os indígenas têm que enfrenta-las recombinando criativamente tais efeitos.

\section{NOTAS}

${ }^{1}$ Como representante da Associação Brasileira de Antropologia, 2006-2010 e 20142015, e também como especialista convidada permanente nos anos entre os dois períodos de representação.

${ }^{2}$ As estatísticas relativas à saúde indígena não são de acesso público. Ao entrar na página da Secretaria Especial de Saúde Indígena e consultar o Sistema de Informações da Atenção à Saúde Indígena (SIASI) o que se encontra são dados populacionais e não de saúde indígena - http://portalsaude.saude.gov.br/index.php/o-ministerio/principal/secretarias/secretaria-sesai/ mais-sobre-sesai/9518-destaques, consultada em 25/09/2017. O SIASI tem sido também objeto de críticas com relação à confiabilidade dos dados levantados (Sousa, M. da C. et al. 2007). Não obstante, tivemos acesso a alguns dados nacionais em agosto de 2008, quando o Departamento de Saúde Indígena (DESAI/FUNASA) fez uma apresentação na CISI com dados da saúde indígena e alguns quadros comparativos com a população geral. Nesta ocasião, apresentou que o coeficiente de mortalidade infantil na população indígena em 2005 era de 52,79, enquanto na população geral era de 21,7 - ou seja, na população indígena a mortalidade infantil mais do que dobrava.

${ }^{3} \mathrm{~A}$ inclusão da noção de interculturalidade na saúde indígena na Argentina é mais recente, datando de 2005 (Lorenzetti 2017).

${ }^{4}$ Embora tal não ocorra nas políticas de educação indígena, na qual a interculturalidade é central para o debate político

${ }^{5}$ A CISI é a comissão que assessora o Conselho Nacional de Saúde para os assuntos relativos à saúde indígena.

${ }^{6}$ Refiro-me ao Decreto no99.438 de 7 de julho de 1990.

7 http://portalsaude.saude.gov.br/index. php/o-ministerio/principal/secretarias/ secretaria-sesai/mais-sobre-sesai/9377-destaques Consultada em 21/09/2017.

${ }^{8} \mathrm{~A}$ integra desse documento pode ser obtida em http://bvsms.saude.gov.br/bvs/ publicacoes/politica saude indigena.pdf Consultada em 21/09/2017.

9 http://portalsaude.saude.gov.br/index. $\mathrm{php} / \mathrm{o}-\mathrm{ministerio} / \mathrm{principal} / \mathrm{secretarias} /$ secretaria-sesai/mais-sobre-sesai/9377-destaques Consultada em 21/09/2017. 
${ }^{10} \mathrm{Na} 4^{\mathrm{a}}$ CNSI em 2006 participaram 372 delegados indígenas (Ministério da Saúde; Conselho Nacional de Saúde 2015:146)

11 Fonte: http://www.funai.gov.br/ index.php/comunicacao/galeria-de-imagens/2599-5-conferencia-nacional-de-saude-indigena?limitstart $=0 \#$. Consultada em 25/09/2017.

${ }^{12} \mathrm{O}$ documentário pode ser acessado em https://vimeo.com/126372482. Consultado em 26/09/2017.

13 Fonte: http://www.funai.gov.br/ index.php/comunicacao/galeria-de-imagens/2599-5-conferencia-nacional-de-saude-indigena?limitstart $=0 \#$. Consultada em 25/09/2017.

${ }^{14}$ Vale destacar nessa direção o Acampamento Terra Livre que desde 2003 se realiza em abril em Brasília. Para os interessados numa perspectiva comparativa entre a $1^{a}$ Conferência Nacional de Política Indigenista (2015) e o Acampamento Terra Livre ver Silva 2017.

${ }^{15}$ Fonte: http://5cnsi.blogspot.com.br/. Consultado em 25/09/2017.

${ }^{16}$ Posso mencionar a palestra Saneamento e Interculturalidade em 2012 no âmbito da reunião da CISI que foi realizada na Rio+20 no Rio de Janeiro e o Guia Educativo sobre Interculturalidade encomendado pela SESAI.

\section{REFERÊNCIAS BIBLIOGRÁFICAS}

Abrams, P. 1988. Notes on the Difficulty of Studying the State (1977). Journal of Historical Sociology Vol. 1 (1), pp.58-89

Bates, R. 1999. Ethnicity, Capital Formation, and Conflict. Social Capital Iniciative, Working Paper \#12, pp. 1-47.

Boccara, G. 2015. La interculturalidad en Chile: entre culturalismo y despolitizaci- ón In: Saúde indigena: politicas comparadas na América Latina, Esther Jean Langdon y Marina Cardoso (orgs.), Florianopolis: EdUFSC, pp.195-216.

Boccara, G., Bolados, P. 2010. ¿Qué es el multiculturalismo? La nueva cuestión étnica en el Chile neoliberal. Revista de Indias, vol. LXX, núm. 250, pp. 651-690.

Bronz, D. 2016. Nos Bastidores do Licenciamento Ambiental. Uma etnografia das práticas empresariais em grandes empreendimentos. Rio de Janeiro: Contra Capa, 480pp.

Cardoso, M. 2015. Políticas de saúde indígena no Brasil: do modelo assistencial à representação política. In: Esther Jean Langdon; Marina D. Cardoso. (Org.). Saúde Indígena: politicas comparadas na América Latina. 1ed.Florianópolis: EdUFSC, pp. 83106.

Ferreira, L. 2015. Interculturalidade e saúde indígena no contexto das políticas públicas brasileiras. In: Esther Jean Langdon; Marina D. Cardoso. (Org.). Saúde Indígena - Politicas comparadas na América Latina. Florianópolis: Editora UFSC, pp. 217-246.

Fóller, M. 2004. Intermedicalidade: a zona de contato criada por povos indígenas e profissionais de saúde. In: Esther Jean Langdon; Luiza Garnelo. (Org.). Saúde dos Povos Indígenas: reflexões sobre antropologia participativa. 1ed.Rio de Janeiro: Contra Capa, pp. 129-147.

Garnelo, L. 2014 “O SUS e a Saúde Indígena: matrizes políticas e institucionais do Subsistema de Saúde Indígena. In: Carla Teixeira; Luiza Garnelo. (Org.). Saúde indigena em perspectiva: explorando suas matrizes bistóricas e ideológicas. Rio de Janeiro: ED FIOCRUZ, pp. 107-144.

Hale, C. 2004. Rethinking Indigenous Politics in the Era of the "Indio Permitido". Nacla Report on the Americas, 38(2):16-21 
IPEA - Instituto de Pesquisa Econômica Aplicada. 2013. Conselhos nacionais: perfil de atuação dos conselheiros. Relatório de pesquisa. Brasília.

IPEA - Instituto de Pesquisa Econômica Aplicada. 2013a.O Conselho Nacional de Saúde na visão de seus Conselheiros. Relatório de pesquisa. Brasília.

Langdon, E.J., Diehl, E., Dias-Scopel, R. "O papel e a formação dos agentes indígenas de saúde na atenção diferenciada à saúde dos povos indígenas brasileiros". In: Teixeira C, Garnelo L, Organizadores. Saúde indigena em perspectiva: explorando suas matrizes históricas e ideológicas. Rio de Janeiro: Editora Fiocruz; pp. 213-39.

Lorenzetti, M. 2017. Los enfoques de salud intercultural en los ámbitos de gestión e investigación en Argentina. Revista de Estudios Marítimos y Sociales, 11, pp. 148-176.

Menéndez, E. 2016. Salud intercultural: propuestas, acciones y fracasos. Ciência \& Saúde Coletiva 21 (1), pp.109-118.

Ministério da Saúde; Conselho Nacional de Saúde. 2015. $5^{a}$ Conferência Nacional de Saúde Indigena: relatório final. Brasília: Ministério da Saúde.

Salviani, R. 2010. Desenvolvimento, antropologia e participação. Uma proposta de reflexão crítica. Anuário Antropológico, v. 2009/I, pp. 227-261.

\section{Participação e Desenvolvi-}

mento Sustentável no Brasil A experiência da Itaipu Binacional. 1. ed. Rio de Janeiro: E-papers, 234pp.

Scopel, D. et al. 2015. Intermedicalidade e protagonismo: a atuação dos agentes indígenas de saúde Munduruku da Terra Indígena Kwatá-Laranjal, Amazonas, Brasil. Cadernos de Saúde Pública (Online), v. 31, p. 2559-2568.

Silva, F. H. 2017. "Por dentro e por fora do estado": estratégias e desafios no proces- so político de constituição do movimento indígena no Brasil contemporâneo. Dissertação (Mestrado em Antropologia) - Universidade de Brasília.

Sousa, M. da C. et al. 2007. O Sistema de Informação da Atenção à Saúde Indígena (SIASI): criação, estrutura e funcionamento. Cad. Saúde Pública vol.23 no.4, pp.853861.

Souza Lima, A. C. 2003. Gestar e Gerir: Estudos para uma Antropologia da Administração Pública. Rio de Janeiro: Nuap/Relume-Dumará, 312pp.

Teixeira, C. 2008. Relaciones de parcerias, políticas públicas y la cuestión de la "pobreza" en Brasil. In: Sanchiz Ochoa, Pilar; Gil Tébar, Pilar. (Org.). Marginación y pobreza en América Latina. Estrategias de supervivencia, políticas gubernamentales y acción social. Andalucía: Signatura Demos, pp. 341-355.

$$
\text { 2010. Autonomia em Saúde }
$$
Indígena: sobre o que estamos falando?. Anuário Antropológico, v. 2009, pp. 99-128.

Teixeira, C.; Silva, C. 2015. The construction of citizenship and the field of indigenous health: A critical analysis of the relationship between bio-power and bioidentity. Vibrant 12 (1), pp.353-384.

Teixeira, C., Simas, D., Costa, N. 2013. Controle social na saúde indígena: limites e possibilidades da democracia direta. Tempus: Actas de Saúde Coletiva, v. 7, pp. 97-115. 